\title{
GENETIC EFFECTS IN CHILDREN EXPOSED IN PRENATAL PERIOD TO IONIZING RADIATION AFTER THE CHORNOBYL NUCLEAR POWER PLANT ACCIDENT
}

\author{
Ye.I. Stepanova*, V.Yu. Vdovenko, Zh.A. Misharina, V.I. Kolos, L.P. Mischenko \\ State Institution "National Research Center for Radiation Medicine of the National Academy of Medical \\ Sciences of Ukraine”, Kyiv 04050, Ukraine
}

\begin{abstract}
Aim: To study the genetic effects in children exposed to radiation in utero as a result of the Chornobyl nuclear power plant accident accounting the total radiation doses and equivalent radiation doses to the red bone marrow. Materials and Methods: Incidence of minor developmental anomalies was studied in children exposed to radiation in utero (study group) and in the control group (1144 subjects surveyed in total). Cytogenetic tests using the method of differential G-banding of chromosomes were conducted in 60 children of both study and control groups (10-12-year-olds) and repeatedly in 39 adolescents (15-17-year-olds). Results: A direct correlation was found between the number of minor developmental anomalies and fetal dose of radiation, and a reverse one with fetal gestational age at the time of radiation exposure. Incidence of chromosomal damage in somatic cells of 10-12-year-old children exposed prenatally was associated with radiation dose to the red bone marrow. The repeated testing has revealed that an increased level of chromosomal aberrations was preserved in a third of adolescents. Conclusion: The persons exposed to ionizing radiation at prenatal period should be attributed to the group of carcinogenic risk due to persisting increased levels of chromosome damage. This article is a part of a Special Issue entitled "The Chornobyl Nuclear Accident: Thirty Years After".
\end{abstract}

Key Words: Chornobyl nuclear power plant accident, prenatal exposure, minor developmental anomalies, chromosomal aberrations.

Assessment of prenatal radiation effects is one of prioritized fields of contemporary radiobiology and genetics. Peculiarities of fetal response to radiation are identified with recognized critical period from ninth till fortieth day upon conception. Risk of unfavorable radiation effects is much higher at this period than that in a case of fetal exposure at later terms [1].

Exposure of pregnant females to ionizing radiation after the A-bombing in Hiroshima and Nagasaki resulted in no excess of congenital malformations (CMF) of dysplastic origin in children. Retardation of somatic and intellectual development was however surveyed in those children mainly exposed at 8-15 weeks of prenatal life. Mental retardation was concomitant to small head size in some children [2]. No such effects were found in persons exposed at prenatal period among population of the villages along the Techa River (Russian Federation) [3] and the Chornobyl nuclear power plant (CNPP) accident survivors [4]. However, some specialists point at the development of cognitive disorders in persons exposed to ionizing radiation in prenatal period [5-7].

Not only the CMF and sentinel phenotype incidence than can be eliminated at antenatal period but the minor developmental anomalies (MDA), i.e. small but stable morphogenetic disorders appearing at early stages of prenatal life, are recently proposed to estimate the consequences of mutagenic and teratogenic effects of environmental impacts [8,9].

Cytogenetic method is one of the leading approaches for biological indication of radiation impact

Submitted: June 13, 2016.

*Correspondence: E-mail: profstepanova@i.ua Abbreviations used: CMF - congenital malformations; CNPP - Chornobyl nuclear power plant; MDA - minor developmental anomalies. in human. Classical method of analysis of solid stained chromosomes is widely applied to assay the radiationinduced chromosomal damage [10, 11]. However, this method is not capable to reveal the entire spectrum of chromosomal damage, thus presently the methods of differential G-banding and fluorescent in situ hybridization of metaphase chromosomes with DNA-probes (FISH) having high resolution are used more often [12].

Objective of this study was to explore the genetic effects in children exposed at prenatal period to ionizing radiation after the CNPP accident. Total radiation doses and red bone marrow equivalent radiation doses were taken into account.

\section{MATERIALS AND METHODS}

Assessment of aftermath of prenatal irradiation was held in pediatric population $(n=1144)$ of the 3 groups. Study group I $(n=340)$ comprised children born by females pregnant at the time of accident who were evacuated from Prypyat city. Study group II $(n=373)$ comprised children born by females pregnant at the time of accident who continued to live in the areas with soil contamination density by ${ }^{137} \mathrm{Cs}$ over $555 \mathrm{kBq} / \mathrm{m}^{2}$ or ${ }^{90} \mathrm{Sr}$ above $111 \mathrm{kBq} / \mathrm{m}^{2}$. In control group $(n=431)$ were children born in 1986 who live in radiologically safe region of Ukraine.

Total fetal radiation doses and fetal red bone marrow equivalent radiation doses did not differ and varied from 10.0 to $376.0 \mathrm{mSv}$ in the study group I. Cumulative total radiation doses for the entire time of living on contaminated territories including antenatal period in children of the study group II were $10.5-72.1 \mathrm{mSv}$, and integral equivalent red bone marrow doses were 14.1-81.7 mSv.

To reveal a range of antenatal risk factors the interviewing of parents was applied with ascertaining 
of parental health, occupational features, presence of bad habits if any, obstetrical and gynecological history, history of pregnancy and delivery in mother, and reviewing of medical records in parents and children.

Clinical check-up and genetic testing included the genealogical evaluation and identification of specific phenotype features in each child from study and control groups. The special Protocol (Card) of registration of the MDA was applied. It included 225 clearly recognizable dysembryogenic stigma grouped according to an anatomical localization principle. Filling in the Protocol provided the accuracy of MDA registration with objective nature and comparability of received data (there were 95\% data agreement in repeated check-up). Data on the present CMF and data on the possible parental exposure to environmental mutagens were entered into the Protocol too. Such approach to assay the mutagenic and teratogenic effects of environmental factors was applied also by the other research teams $[8,9]$.

Cytogenetic studies were held upon a complex clinical check-up and medical-genetic counseling. Children have had neither acute nor exacerbation of chronic diseases within three months before examination. No preventive vaccinations were introduced too, i.e. principal factors that could make any bias in cytogenetic tests were excluded. The first cytogenetic test was applied in 60 children 10-12-year-old of the study group I $(n=23)$, study group II $(n=22)$, and control group $(n=15)$. The repeated cytogenetic examination was held in 39 children 16-17-year-old of the study group I $(n=16)$ and study group II $(n=23)$.

Differential G-banding of chromosomes was done according to the modified of Yunis [13]. Application of this method enables to receive the early mitotic chromosomes with high segmentation degree (550-1500 in a haploid set) and to define their structural damage with identification of breakpoints at the segment and subsegment levels [14]. The analysis was held with a visual karyotyping of individual chromosomes using oil immersion at $\times 1000$ magnification . At least 200 metaphases corresponding to the specific requirements were analyzed in each subject. All the chromosome type and chromatid type aberrations, i.e. single fragments and exchanges were accounted except gaps. Both unstable (i.e. free paired fragments, acentric rings, dicentric chromosomes, and centric rings) and stable aberrations (i.e. translocations, terminal and interstitial deletions, para- and pericentric inversions, insertions leading to formation of abnormal monocentric chromosomes) were accounted as the markers of radiation impact.

Data processing was held using the Microsoft Excel and Statistica software. The Spearman's rank correlation non-parametric test (Ro) was calculated allowing to set the relationship between qualitative and quantitative characteristics [15].

All studies were performed as part of our clinical standard procedures and within the approved indications. An analysis was approved by the Institutional
Review Board. Written informed consent was obtained from all patients. No prospective experiments with human subjects were performed and the study was in accordance with the Helsinki Declaration and our national regulations.

\section{RESULTS AND DISCUSSION}

Children of the study groups were not different from the control group by the medical and biological risk factors and bad habits in parents, i.e. smoking or alcohol abuse (Table). Impact of these factors along with fetal radiation exposure predisposed to the increased incidence of morphogenetic variants characterized by multiple MDA. Number of such children in both study groups I and II was higher vs that in control group: 43.2; 33.6 , and $11.9 \%$, respectively $(p<0.05)$.

Table. Incidence of some risk factors in children of the study and control groups (\%)

\begin{tabular}{lccc}
\hline \multicolumn{1}{c}{ Risk factor } & $\begin{array}{c}\text { Study group I } \\
(\mathrm{n}=340)\end{array}$ & $\begin{array}{c}\text { Study group II } \\
(\mathrm{n}=373)\end{array}$ & $\begin{array}{c}\text { Control group } \\
(\mathrm{n}=431)\end{array}$ \\
\hline Occupational hazards in a father & $19.2^{*}$ & 3.4 & 2.8 \\
Bad habits in parents & 20.8 & 21.6 & 25.1 \\
Chronic somatic diseases: & & & \\
- in a father & 19.2 & 17.9 & 19.4 \\
- in a mother & 22.2 & 19.2 & 20.5 \\
Late first delivery & 12.9 & 13.4 & 10.4 \\
Repeated deliveries after 35 years & 18.5 & 19.2 & 20.1 \\
Burdened obstetrical history & 18.5 & 26.9 & 26.4 \\
Complicated pregnancy & 44.9 & 40.4 & 41.1 \\
Complicated labor & 57.4 & 59.6 & 61.7 \\
Radiation factor & 100.0 & 100.0 & - \\
\hline
\end{tabular}

Note: ${ }^{*}$ difference between the study and control groups is significant $(p<0.05)$.

Number of MDA per one child was $5.58 \pm 0.26$ in the study group I, $5.13 \pm 0.32$ in the study group II, and $2.95 \pm 0.16$ in control $(p<0.001)$. The most pronounced differences were found in the spectrum of MDA in locomotor system where their average amount in the study groups I and II twice exceeded the values in control group $(1.43 \pm 0.10 ; 1.22 \pm 0.09$, and $0.64 \pm 0.06$, respectively; $p<0.001$ ).

A direct correlation was found between the MDA number in a child and total fetal irradiation dose $(\mathrm{Ro}=0.61 ; p<0.002)$, and a reverse correlation was revealed between the MDA number and gestation age at the time of radiation exposure $(\mathrm{Ro}=-0.53$; $p<0.003$ ). The highest number of MDA was registered in persons exposed to ionizing radiation in the terms of 2 to 8 weeks of prenatal life $(\mathrm{Ro}=-0.91 ; p<0.0001)$.

Consequently the lesser fetal gestation age was at the time of irradiation and the higher radiation dose was, the higher number of MDA has been revealed in a child.

It is believed that impact of environmental of endogenous teratogenic or mutagenic factors at early terms of prenatal life can lead not only to the CMF development but also to origination of small but stable disorders of morphogenesis, i.e. MDA [8, 9].

Cytogenetic testing results indicate that the indices in the control group were in general corresponding to contemporary literature data on the spontaneous levels of chromosomal aberrations in population and were in agreement with conclusions of some experts about the acceleration of spontaneous mutagenesis 
during the last 10 years. The last fact can be related to environmental degradation [16].

An increased incidence of structural chromosomal anomalies $(9.07 \pm 1.34$ per 100 cells vs $2.47 \pm 0.28$ in the control group; $p<0.01$ ) with domination of stable damages $(5.64 \pm 0.94$ per 100 cells vs $0.43 \pm 0.19$ in control; $p<0.05$ ) and preferential localization in chromosomes $1,3,5,7,11,13$, and 17 were found at remote period after the CNPP accident in children exposed to acute irradiation in prenatal life (study group I). Majority of the stable-type aberrations were represented by deletions $(4.18 \pm 0.71$ per 100 cells vs $0.37 \pm 0.19$ in control; $p<0.05$ ) with predominance of terminal ones. Translocations and inversions found in about the same incidence $(0.70 \pm 0.16$ and $0.75 \pm 0.15$ in average per 100 cells, respectively) occurred much more rarely. Unstable chromosomal aberrations found in $1.43 \pm$ 0.35 per 100 cells vs $0.47 \pm 0.13$ in control $(p<0.05)$ were represented by the acentric fragments $(0.66 \pm$ 0.18 per 100 cells), dicentric chromosomes $(0.61 \pm$ 0.15 per 100 cells) and ring chromosomes (0.16 \pm 0.05 per 100 cells).

An average incidence of chromosome aberrations in the study group II was $7.63 \pm 2.92$ per 100 cells what significantly exceeded these values in control group ( $2.47 \pm 0.28$ per 100 cells; $p<0.05$ ). There was an increased number of both stable $(4.23 \pm 1.06$ per 100 cells vs $0.43 \pm 0.19$ in control group; $p<0.05$ ) and unstable $(1.75 \pm 0.25$ per 100 cells vs $0.47 \pm$ 0.13 in control group; $p<0.05$ ) induced chromosomal aberrations and a doubled damage of chromosomes 1 , $4,5,9,17$, and 22. Deletions ( $3.38 \pm 0.87$ per 100 cells) mostly of terminal type, translocations $(0.48 \pm 0.14$ per 100 cells), and inversions ( $0.38 \pm 0.06$ per 100 cells) were featured among the stable structural rearrangements. Unstable chromosomal aberrations were represented by the acentric fragments $(1.10 \pm 0.19$ per 100 cells), dicentric $(0.46 \pm 0.09$ per 100 cells $)$ and ring chromosomes $(0.20 \pm 0.08$ per 100 cells).

Number of chromatid-type aberrations in children of the study group I ( $2.0 \pm 0.25$ per 100 cells $)$ and study group II ( $1.65 \pm 0.20$ per 100 cells) was not significantly different from these in control group $(1.57 \pm 0.28$ per 100 cells; $p>0.05$ ).

A moderately strong correlation of the fetal red bone marrow equivalent radiation dose and number of aberrant cells $(\mathrm{Ro}=0.50 ; p<0.02)$, chromosome-type aberrations $(\mathrm{Ro}=0.53 ; p<0.01)$, translocations $(\mathrm{Ro}=0.60$; $p<0.003$ ), and deletions ( $\mathrm{Ro}=0.60 ; p<0.003$ ) was found in prenatally irradiated children born to females evacuated from the Prypyat city (study group I).

Significant correlation between cumulative equivalent radiation doses to the red bone marrow for the entire period of residence in contaminated areas and the number of aberrant cells ( $R o=0.62 ; p<0.002$ ), chromosome-type aberrations ( $\mathrm{Ro}=0.72 ; p<0.0003)$, stable $(\mathrm{Ro}=0.64 ; p<0.003)$ and unstable $(\mathrm{Ro}=0.58$; $p<0.01)$ chromosome damages was found in children who have experienced a prolonged exposure to radiation factor both in utero and at later periods (study group II). No dependence of the chromatid-type aberrations on red bone marrow irradiation dose was found.

Other researchers have also stated the increased incidence of chromosome damage in peripheral blood lymphocytes of children exposed to acute and longterm irradiation at prenatal and postnatal periods [17, 18]. However, higher incidence of stable and unstable chromosomal aberrations found in our study could be related to application of differential G-banding with much better resolution capacity than that of routine solid staining method applied by other research teams. Higher radiation doses received by the subjects in our study could be of importance as well.

The repeated cytogenetic testing has revealed higher incidence of chromosomal damage in 37.5\% of 15-17-year-old adolescents in the study group I and in $30.4 \%$ of them in the study group II vs the control group.

Incidence of chromosomal aberrations in adolescents from the study group I was $3.60 \pm 0.04 \%$ per 100 cells.

Integrally the 20 out of 22 autosomes were involved in the revealed disorders. Among different types of structural chromosomal rearrangements the deletions and translocations (41.67 and $16.67 \%$, respectively) were the most prevalent. Inversions were detected in $5.56 \%$, dicentric chromosomes in $2.78 \%$, ring chromosomes in $5.56 \%$, and paired fragments in $5.56 \%$ of all accounted aberrations.

Incidence of chromosomal aberrations in adolescents born and constantly living in radiologically contaminated regions (study group II) was $4.16 \pm 0.04 \%$ per 100 cells.

According to data analysis, the deletions and translocations (62.0 and $10.0 \%$ of all injuries) were most prevalent among all types of chromosomal rearrangements. Inversions and unstable aberrations such as paired fragments and ring chromosomes were found more rarely, namely in $4.0 ; 8.0$, and $2.0 \%$, respectively. The 20 out of 22 autosomes were involved in the revealed cytogenetic abnormalities.

In conclusion, the received results are indicative of the positive trend. Incidence and spectrum of cytogenetic abnormalities are however exceeding the spontaneous level of mutagenesis in $37.5 \%$ of adolescents in the study group I and in $30.4 \%$ of them in the study group II $(p<0.05)$ at the age of $15-17$ years. All these disorders highlight the destabilization of hereditary structures, thereby increasing the risk of multifactorial diseases, the high frequency of which was observed by many researchers in children exposed in utero [17-19]. Our results suggest that a phenomenon of genome instability characterized by the presence of multiple morphogenetic variants of MDA and increased incidence of chromosomal aberrations persisting for a long time is developed in individuals exposed to radiation in utero. It is known that people with high levels of structural chromosomal damage can be attributed to the group of carcinogenic risk. Translocations are the most common chromosomal 
abnormalities that are characteristic for hematological malignancies and some solid tumors [20]. Studies of the Japanese authors conducted in population that had survived the A-bombing in Hiroshima and Nagasaki have shown a correlation between the translocation in cells of red bone marrow and leukemia [21]. There is an evidence of increased cancer risk in persons exposed to ionizing radiation in prenatal period to the doses exceeding $0.5 \mathrm{~Gy}$, whereas the effect of lower doses remains debatable [22]. Impact of radioactive iodine resulted in an increased incidence of papillary thyroid cancer in children of all age groups including the irradiated in prenatal period that is the very severe unfavorable effect of the CNPP accident [23].

Thus, the increased levels of chromosome aberrations may be used as a prognostic test for the selection of carcinogenic risk groups among subjects exposed to ionizing radiation in utero after the CNPP accident.

\section{REFERENCES}

1. Buldakov LA, Kalistratova VS. Radioactive Radiation and Health. Moscow: Inform-Atom, 2003. 165 p. (in Russian).

2. Schull WJ, Otake M, Yoshimura H. Radiation related damage to the human brain. In: Low Dose Radiation: Biological Basis of Risk Assessment. KF Baverstock, JW Stather, eds. London: Taylor \& Francis, 1989: 28-41.

3. Evtushenko NN. Certain characteristics of the perinatal development of children whose parents were exposed to the action of uranium fission products. Pediatriia 1991; (12): 33-7 (in Russian).

4. Stepanova E, Vdovenko V, Misharina Zh. Genetic and somatic effects of intrauterine irradiation. In: Health Effects of the Chornobyl Accident: A Quarter of Century Aftermath. A Serdiuk, V Bebeshko, D Bazyka, S Yamashita, Eds. Kyiv: DIA, 2011: 563-72.

5. Busby C, Lengfelder E, Pflugbeil S, Schmitz-Feuerhake $\mathrm{I}$. The evidence of radiation effects in embryos and fetuses exposed to Chernobyl fallout and the question of dose response. Med Confl Surviv 2009; 25: 20-40.

6. Bazyka DA, Loganovsky KM, Ilyenko IM, et al. Gene expression, telomere and cognitive deficit analysis as a function of Chornobyl radiation dose and age: from in utero to adulthood. Probl Radiac Med Radiobiol 2015; (20): 283-310.

7. Heiervang KS, Mednick S, Sundet K, Rund BR. Effect of low dose ionizing radiation exposure in utero on cognitive function in adolescence. Scand J Psychol 2010; 51: 210-5.

8. Bochkov NP, Subbotina TI, Yakovlev VV, et al. Study of inborn morphogenetic variants in children. Gig Sanit 1994; (3): 53-5 (in Russian).
9. Ginzburg BG. Methods for determining of the frequency of congenital malformations and congenital morphogenetic variants in children within genetic monitoring system. Pediatriya 1999; (4): 41-4 (in Russian).

10. Kuzmina NS, Suskov II, Sadovnikov VP, et al. Integrated monitoring of genetic status of children living in areas of the Bryansk region contaminated with radionuclides due to the Chernobyl accident. Ecol Syst Devices 2003; (7): 41-6 (in Russian).

11. Sevan'kaev AV, Mikhailova GF, Potetnia OI, et al. Results of the dynamic cytogenetic study of children and teenagers living in areas, radioactive by contaminated after the Chernobyl accident. Radiats Biol Radioecol 2005; 45: 5-15 (in Russian).

12. Shevchenko VA, Snigireva GP. The significance of cytogenetic investigation for the estimation of Chernobyl accident consequences. Radiats Biol Radioecol 2006; 46: 133-9 (in Russian).

13. Yunis JJ. High resolution of human chromosomes. Science 1976; 191: 1268-70.

14. Stepanova EI, Misharina ZhA, Vdovenko VYu. Long-term cytogenetic effects in children prenatallyexposed to radiation as a result of the accident at the Chernobyl Atomic Energy Station. Radiats Biol Radioecol 2002; 42: 700-3 (in Russian).

15. Rebrova OYu. Statistical analysis of medical data. Moscow: Media Sphera, 2002. 305 p. (in Russian).

16. Pilinska MA, Dybskiy SS. FISH detection of spontaneous level of chromosome aberrations in peripheral blood lymphocytes in persons of different ages. Tsitol Genet 2004; 38 (4): 62-6 (in Ukrainian).

17. Sipiagina AE, Baleva LS, Suskov II. Increased sensitivity to low doses of radiation as a basis for the formation of chronic somatic diseases in children. Russ Bull Perinatol Pediatrics 2004; 5: 43-7 (in Russian).

18. Baleva LS. Radiation ecopathology of pediatric age as an actual problem of modern pediatrics. In: Children's Health and Radiation: Current Problems and Solutions, Vol 2. LS Baleva, Ed. Moscow: Informpoligraf, 2006: 4-8 (in Russian).

19. Lomat LN. The health of children exposed to ionizing radiation in utero. Int J Radiat Med 2001; (3): 227 (in Russian).

20. Fleishman YeV. Carcinogenesis. Moscow: Nauchnyi Mir, 2000: 342-60 (in Russian).

21. Bond VP. Dose, effect severity, and imparted energy in assessing biological effects. Stem Cells 1995; 13 (Suppl 1): 21-9.

22. Brent RL. Protection of the gametes embryo/fetus from prenatal radiation exposure. Health Phys 2015; 108: 242-74.

23. Cardis E, Hatch M. The Chernobyl accident - an epidemiological perspective. Clin Oncol (R Coll Radiol) 2011; 23: $251-60$. 